\title{
Cultura Digital na Escola ou Escola na Cultura Digital?
}

\author{
Daniela Stevanin Hoffmann - PGIE/UFRGS - dani@ lec.ufrgs.br * \\ Léa da Cruz Fagundes - PGIE/LEC/UFRGS - leafagun@ufrgs.br ${ }^{* *}$
}

Resumo: A proposta deste artigo é analisar e discutir o uso da informática na escola pública. Pesquisadores de áreas tecnológicas e humanistas criticam a insuficiência de pesquisas que subsidiem as políticas públicas responsáveis por tais iniciativas. Há uma extensa produção de estudos que vêm sendo documentados sobre múltiplas variáveis no fenômeno "informática na escola", mas, em sua maioria, são pontuais e buscam resultados evidentes à luz de avaliações objetivas sem priorizar as relações entre Cultura Digital e Instituição Escolar. No Brasil, assim como em outros países, experiências piloto buscam novos modelos. O Projeto Um Computador por Aluno abre possibilidades para uma mudança de paradigma educacional. Explora-se a inversão de direcionamento na inclusão digital para que não mais a Cultura Digital seja introduzida apenas como ferramenta na Escola, mas que esta se inclua na Cultura Digital.

Palavras-Chave: cultura digital; instituição escolar; laptop educacional.

Digital Culture at School or School at Digital Culture?

Abstract: The purpose of this paper is to analyze and discuss the use of technology in public school. Researchers from technological and humanist areas criticize the lack of research that subsidizes public policies responsible for such initiatives. There is an extensive production of studies that have been documented on many variables present in the phenomenon "technology in school", but their majority is punctual and seeks results guided by objective assessments without give priority to relations between Digital Culture and Educational Institution. In Brazil, as in other countries, pilot experiences seek new models. The Project "Um Computador por Aluno" triggers possibilities for a change of educational paradigm. There is an exploration of a reversal of direction in digital inclusion in order to Digital Culture no longer be introduced at School as a tool, but as means to this last one to be included in Digital Culture.

Key-words: digital culture; school institution; educational laptop.

\section{Introdução}

Cultura é a representação das manifestações humanas; aquilo que é aprendido e partilhado pelos indivíduos de um determinado grupo. A Cultura Digital é a cultura de rede, a cibercultura que sintetiza a relação entre sociedade contemporânea e Tecnologias da Informação (TIs). Ao mesmo tempo que a Cultura Digital abriga pequenas totalidades e seus significados, mantém-se desprovida de um sentido global e único. Esta é a cultura da diversidade, da liberdade de fluxos, de conhecimentos e de criações que dá corpo e identidade às organizações que delas se constituem (Amadeu, s.d.). É a cultura dos filtros, da seleção, das sugestões e dos comentários (Costa, 2002).

É uma proposição plausível que se a Cultura é Digital, seus instituidores também são informatizados, não é mesmo? Porém, as relações humanas nem sempre obedecem à lógica: o mesmo grupo que legitimiza e fomenta o desenvolvimento e a expansão da tecnologia não está, em sua totalidade, vivendo a inclusão digital.

As consequiências do desenvolvimento das TIs são visíveis nas expressões 
2

culturais, nas noções de espaço e tempo, na disseminação de informações, etc. A estrutura social, representada pela informação e pela transformação tecnológica, pode ser classificada como um modelo cultural de interação e organização (Castells, 1999). As expressões culturais são predominantemente mediadas pelas redes de comunicação eletrônica abertas ao público em geral e não mais exclusivamente a uma elite. As noções de espaço e tempo são transformadas pela superação de empecilhos como distâncias físicas e diferenças de fuso horário. A informação circula por todo o mundo ao acesso de um clique.

As TIs proporcionaram rapidez e agilidade à disseminação de notícias, fatos e teorias. As comunicações tornaram-se instantâneas. A ampliação e a valorização da diversidade mundial, a partir do século XIX, tornaram o crescimento dos conhecimentos técnicos e científicos incontrolável. Dessa forma, qualquer intenção em dominar "os saberes adequados" tornou-se ilusória. O mundo contemporâneo está sofrendo uma mutação na relação com o saber (Lévy, 1999).

A produção de conhecimento em grandes escala e velocidade vem fazendo com que a maioria das habilidades e competências valorizadas socialmente estejam sempre à frente da Escola. A necessidade de administrar, explorar, selecionar e julgar informações e suas diversas versões está, ainda, sendo preterida pela listagem de conteúdos dos currículos escolares que perduram sem modificações significativas há décadas (Lévy, 1999). O uso da informática e das mídias comunicacionais intensificou o processo de distribuição de conhecimento para além dos centros acadêmicos. Mesmo assim, a Escola é a instituição social mais resistente a essas mudanças.

Lamentavelmente, quando se propõe modificações nos programas de educação para integrar as novas tecnologias digitais, ocorre que o ponto de vista bairrista é tão arraigado que estas iniciativas, muitas vezes, só servem para proteger o status quo, para fazer mais do mesmo (repeti-lo). Se muda simplesmente o "suporte" para que nada mude... Não se pensa na integração dos conhecimentos dentro de uma escola, entre as mesmas escolas e entre regiões e países (Battro \& Denham, 1997).

Instituições são reguladores do funcionamento da sociedade e das interações sociais especialmente as relacionadas com o que é público/estatal. Esses produtos e representantes do interesse social deveriam, como tais, atuar em sincronia com a estrutura, a economia e a cultura da rede em que está inserida. A Escola como instituição, ou seja, como produto dos interesses da sociedade, teoricamente, deveria estar em sintonia com as demandas externas a ela. Mas não está.

No contexto tecnológico atual, são valorizadas as habilidades, atitudes e competências do Sujeito da Sociedade em Rede (Hoffmann, 2006). A Escola poderia, então, dedicar-se a enriquecer ambientes de aprendizagem para que o aprendiz possa pensar sobre situações-problema em diversas perspectivas e criar suas alternativas de soluções, integrando conhecimentos e trabalhando em equipe.

Os Parâmetros Curriculares Nacionais (2002) mostram que a intenção de mudança, de aproximação entre a formação escolar tradicional e a necessária, está declarada e respaldada na medida em que o documento valoriza "a capacidade de pesquisar, buscar informações, analisá-las e selecioná-las" e "a capacidade de aprender, criar, formular, ao invés do simples exercício da memorização" (p. 16). Entretanto, prevalecem nas Escolas, grandes conjuntos teóricos historicamente estabelecidos, aceitos sem discussão e apresentados aos alunos pelo professor. Essa prática, geralmente, incorre na idéia de que para aprender basta aceitar (passivamente) o que for apresentado, sem possibilidade de reinventar, de descobrir, de pensar.

Construir, criar, inventar, experimentar, comunicar, cooperar, ajudar, aprender ... 
3

essas são as palavras de ordem da mudança. Verbos, esses e tantos os outros, indicadores de ações, de movimento, de avanço. A Escola precisa movimentar-se para integrar-se a Cultura Digital, formando uma amálgama inseparável, que dá lugar aos indivíduos e suas ações. Segue-se discutindo a distância entre as Escolas existentes e as que são necessárias, analisando a situação atual, apresentando sugestões, integrando teoria e prática nos relatos e pensando no futuro que já começou.

\section{Técnicas e Materiais}

O trabalho com variados recursos didático-pedagógicos, físicos e virtuais, que coloquem o aluno em interação com diversos conceitos é uma alternativa para a Escola. As formas conceituais (objetos "reais", objetos virtuais, representações, esquemas, fotos, vídeos, produções hipertextuais, linguagem de programação, etc.) nas quais os alunos tenham oportunidade de agir sobre, a fim de conhecer e operar com suas propriedades devem ser diversas e diversificadas. As situações-problema nas quais os alunos encontrem significado e possam se envolver criativamente devem ser exploradas frequientemente. As trocas entre os pares e com o professor devem ser proporcionadas regularmente. Com esforços nesse sentido, a Escola ofereceria maiores probabilidades de que conceitos sejam aprendidos e não simplesmente decorados e repetidos (Piaget, 2002).

As interações entre os próprios alunos e entre os alunos e o professor é parte importante na mudança de paradigma. Uma Escola que prioriza o fazer do aluno, suas estratégias próprias e suas construções oportunizaria as trocas argumentativas a fim de trabalhar a sistematização dos conceitos e a formulação coletiva. Quando o sujeito encontra experiências, testagens, bibliografias, opiniões, etc. que divergem do seu posicionamento, ele volta-se para a própria produção a fim de analisá-la e confirmá-la ou refutá-la. Assim, o sujeito repensa suas atividades, modificando-as, expandindo-as ou fortalecendo os argumentos construídos por ele (Fagundes et al, 2000).

Os processos de seleção de informações, testagem, proposição de alternativas de solução e organização e apresentação de resultados são necessários para a construção de conhecimento (Nevado, 2001). A problematização, a reflexão e a argumentação acerca de situações-problema pode mobilizar uma discussão presencial ou virtual, com o suporte de recursos digitais como fóruns, listas de discussão de e-mail, etc. Os principais ganhos no uso de TIs na mediação desses debates é o registro e a visibilidade: a escrita pode ser guardada por tempo indeterminado em blogs, wikis, Ambientes Virtuais de Aprendizagem (AVAs), etc. para consultas posteriores; e, uma vez na Internet, o conteúdo é público e a discussão pode receber contribuições externas ao grupo no qual ela foi gerada.

Essa idéia muitos tiveram e alguns implementaram. A quantidade de computadores com acesso a Internet instalados nas escolas públicas brasileiras é crescente. As escolas abrem janelas para a comunicação com o mundo. O governo começa a experimentar o modelo 1:1 (1 para 1), isto é, o projeto Um Computador por Aluno (UCA), em cinco escolas públicas. Os pilotos brasileiros são acompanhados de perto por pesquisadores de universidades próximas a essas escolas. Sobre a experiência em Porto Alegre, faremos referência adiante.

Especialistas dedicam-se a estudar as conseqüências do fenômeno do computador na Escola. Um estudo recente apresentou resultados contrários à idéia de que essas máquinas seriam potencializadoras educativas e indicou que os alunos que dizem estudar utilizando o computador têm desempenho inferior aos que não fazem uso 
4

dele (Dwyer, 2007). Outros estudos identificam avanços no desenvolvimento cognitivo de crianças e adultos (alunos e professores) que utilizam o computador para fins de estudo $^{1}$. As pesquisas têm abordado a questão da introdução da Informática na Educação da mesma forma que abordavam, na década de 90, a influência da mídia na Educação. O ponto de análise é no sentido tecnologia-escola, o que a primeira causa na segunda.

Dentro dessa perspectiva, incluir digitalmente é possibilitar acesso as TIs e a Internet para que a tecnologia e a rede de computadores passem a fazer parte da realidade do indivíduo ou da instituição beneficiada. Entretanto, inclusão digital não pode ser restrita a acesso: incluir é envolver, inserir e relacionar; é fazer parte, é causa e efeito; é possibilitar o acesso à informação bem como a produção de informação. A entrada da Internet na Escola está realmente incluindo essa instituição na Cultura Digital ou está apenas permitindo que a Escola tome conhecimento dessa Cultura? A diferença está no que a Escola faz a partir do contato com o mundo além dos seus horizontes: ela recebe as informações e as utiliza no seu modelo tradicional como se o computador fosse um livro didático infinito? Faz da máquina, conectada à rede, uma grande ferramenta de pesquisa que poderá servir para auxiliar na realização de inúmeros trabalhos escolares como se pesquisava em bibliotecas, em enciclopédias? Ou usa a rede para compartilhar suas produções? A Escola emite tanto quanto recebe? Oportuniza a expressão livre? Propicia e incentiva a cooperação entre indivíduos, internos ou externos à instituição? Permite a visualização do que é feito dentro de seus limites físicos? A Escola se expõe? Faz dos trabalhos escolares pesquisas de domínio público que contribuem para a construção de conhecimentos na rede?

A Instituição Escolar no compasso da Cultura Digital seria aberta, democrática, dinâmica e não hierarquizada pelo domínio do saber. Entretanto, a maioria dos esforços para incluir a Escola na Era Digital tem sido no sentido de possibilitar que ela acesse (passivamente) o exterior, mas não necessariamente atue nele para modificá-lo. O que normalmente acontece é que o computador entra na Escola, o acesso a Internet é possibilitado e a sala de informática fica trancada à espera de um especialista que a coordene. $\mathrm{O}$ então chamado Laboratório de Informática torna-se uma biblioteca virtual de pesquisas do tipo $C t r l C+C t r l V$ (copia e cola), uma sala de jogos e recreação para substituir um professor ausente, uma sala de bate-papo, etc., ou seja, ou os alunos são direcionados a "pesquisar" sobre determinado assunto ou são liberados para ocupar-se livremente. Nessa segunda opção, percebe-se que a maioria dos alunos recorre a jogos, sites de relacionamento e ferramentas de comunicação online, dependendo da faixa etária. A grande oportunidade que a Escola perde é a de canalizar essa pré-disposição de seus alunos, principalmente os adolescentes, em se comunicar.

$\mathrm{Na}$ experiência com laptops educacionais que está sendo realizada em uma escola pública de Porto Alegre, a discussão sobre estratégias de utilização do laptop na prática pedagógica aborda esse tema. $\mathrm{O}$ posicionamento da equipe da escola se reflete nas (re)organizações de tempos, espaços físicos, carga horária, funções da estrutura institucional, posturas dos alunos, etc. A Escola Estadual de Ensino Fundamental Luciana de Abreu (LA), em parceria com o Laboratório de Estudos Cognitivos da Universidade Federal do Rio Grande do Sul (LEC/UFRGS) e a Secretaria de Educação a Distância do Ministério da Educação (SEED/MEC) integra, com outras quatro escolas brasileiras, o Projeto $\mathrm{UCA}^{2}$.

A idéia do laptop educacional de baixo custo têm origem em uma Organização Não-Governamental (ONG) fundada, no ano de 2005, por Nicholas Negroponte e sua 
5

equipe de pesquisa. A proposta da ONG americana OLPC (One Laptop Per Child) ${ }^{3}$ tem cinco princípios orientadores, dentre os quais destacamos dois: saturação e conectividade. O primeiro diz respeito à inserção dos laptops em uma comunidade inteira (bairro, vila, cidade, país, etc.) para que as interações formem uma rede de aprendizagens coletivas que, na medida em que se estabelecer e se fortalecer, possibilite a expansão dessa comunidade. $\mathrm{O}$ segundo refere-se à conexão sem fio entre os próprios laptops (Rede Mesh) e a Internet. Com a possibilidade de interação, mesmo que não haja acesso a web, as crianças podem dividir suas descobertas, encontrar interesses comuns, conversar em um bate-papo, compartilhar uma atividade (que é equivalente a utilizar um mesmo software simultaneamente), aprender e construir em equipe.

Em junho de 2005, quando o então presidente Luis Inácio Lula da Silva conheceu a proposta da OLPC, começou a iniciativa do Governo Federal para a inserir laptops educacionais de baixo custo em escolas públicas do sistema de ensino no país. No que se refere à experiência em Porto Alegre, o LEC/UFRGS presta assessoria à escola piloto propondo a utilização do laptop a partir Projetos de Aprendizagem (PAs), na qual o computador é mais do que uma ferramenta de pesquisa. A proposta pedagógica dos PAs, resumidamente, é oportunizar aos alunos que realizem pesquisas sobre assuntos de seu interesse. Esses iniciantes 'projetos de pesquisa' são orientados pelos professores que, além de auxiliar o aluno a estruturar sua pesquisa, buscam explorar os conceitos das diversas áreas que podem ser relacionados ao PA. Assim, o processo de aprendizagem torna-se cooperativo e interdisciplinar e os conteúdos escolares são explorados e estudados a partir da necessidade gerada pelos PAs (Fagundes et al, 2000; Lacerda et al, 2000).

No trabalho com PAs, várias mudanças tendem a ocorrer: a reconfiguração do espaço físico da sala de aula; a gradual integração das áreas do conhecimento, dos professores e dos alunos (entre os próprios e uns com os outros); a desfragmentação do horário escolar; a criação de um novo currículo; o desenvolvimento da postura investigativa; o papel do professor, do aluno e toda comunidade escolar; a inserção da família na escola e na aprendizagem dos alunos; entre outros tantos que este texto não irá tratar (Lacerda \& Dutra, 2003). O artigo concentra-se nos processos de comunicação e nos movimentos resultantes nas atuações de professores, alunos e famílias.

Esta mudança de papéis é positiva porque a escola do futuro, desligada de muitas imposições curriculares, graças a um melhor emprego das novas tecnologias digitais a distancia para distribuir conhecimentos, será cada vez mais importante no processo de socialização das crianças e adolescentes. Se converterá em um âmbito de encontro mais criativo e aberto ao mundo (Battro \& Denham, 1997).

\section{Resultados e Discussão}

A LA está, dentro do contexto apresentado, vivendo modificações em sua própria estrutura: é um movimento da Instituição Escolar para integrar-se a Cultura Digital. A entrada do computador na sala de aula balança as estruturas tradicionais, principalmente, porque o foco de atenção não é mais o professor ao quadro negro; cada aluno tem, em suas mãos, uma ligação com o mundo exterior à sala de aula e, fazendo uso dessa conexão, pode dedicar-se ao que lhe interessa, ao que lhe chama a atenção, ao que lhe oferece satisfação e prazer. A maioria dos professores, por mais que também tenham o seu próprio laptop e, com isso, as mesmas oportunidades dos alunos em expandir horizontes, não tem fluência para utilizar essa ferramenta, nem com propósito pessoal, nem com intenções educacionais.

O primeiro abalo na estrutura tradicional do saber a ser transmitido pelo 
6

professor acontece na medida em os alunos encontram na Internet fontes de informação muito mais variadas e atualizadas do que as trazidas por seus professores. As hierarquias de poder são gradualmente contestadas e o professor é destituído da sua antiga posição de controle. Nessa rede em que todos tem as mesmas condições de adquirir e construir conhecimentos, o papel do professor precisa se modificar: ele passa a valorizar o interesse do aluno e elabora seu planejamento e implementa sua prática a partir do aluno e não mais da grade curricular (Lévy, 1999).

$\mathrm{Na}$ escola LA, os professores vivem essa transição e buscam inserir-se nos movimentos dos alunos que estão muito mais incluídos na Cultura Digital que a própria Escola. As tentativas de institucionalizar o laptop não tiveram sucesso: restringir tempo de uso, vigiar e proibir acesso a determinados sites, proibir a interação via ferramentas digitais de comunicação e punir com a retirada temporária do laptop do aluno foram ações executadas por diversos professores. Tentativas no sentido de incluir a Cultura Digital na sala de aula foram implementadas com maior aceitação entre os alunos: utilizar o computador para fazer pesquisas que ilustrem o conteúdo explicado ou que respondam às questões apresentadas pelo professor, recompensar os alunos liberando o uso do laptop para qualquer finalidade - desde que a turma fique em silêncio durante uma explanação e faça as atividades que o professor ofereceu - e usar as ferramentas digitais de comunicação para entregar trabalhos foram as alternativas de outros professores.

Aconteceram, também, ações no sentido de incluir a escola na Cultura Digital, modificando o paradigma educacional e, conseqüentemente, contribuindo com o desenvolvimento de indivíduos com habilidades, competências e atitudes valorizadas socialmente. Essas ações oportunizadas e realizadas por alguns professores tiveram uma série de efeitos na comunidade escolar como um todo, identificáveis nas atitudes dos alunos, dos próprios professores e das famílias dos alunos. Serão apresentados e discutidos três casos-exemplo. O primeiro é sobre a formação em serviço dos professores e o uso da lista de discussão de e-mail que decorrem da reflexão sobre situações de sala de aula. O segundo caso aborda, a partir dos registros dos alunos em ambiente virtual, a identificação dos conteúdos atitudinais, procedimentais e conceituais emergidos de PAs. O terceiro fala da participação da família na escola, desencadeada pela curiosidade dos pais sobre o laptop.

A equipe de pesquisadores da UFRGS, membros do LEC e doutorandos do Programa de Informática na Educação (PGIE), que assessora a escola desde o princípio do Projeto, em janeiro de 2007, não poderia (nem gostaria) de estar atuando na sala de aula em tempo integral. Tanto por questões de disponibilidade da equipe quanto (e principalmente) por questões metodológicas: se a pesquisa fosse sobre a atuação dos pesquisadores seria aceitável, mas a proposta é para a Escola, para que o grupo de professores e alunos conheça possibilidades pedagógicas que a ferramenta tecnológica desencadeia. Assim, os esforços da equipe de pesquisa concentram-se na formação em serviço dos professores.

Nessa relação escola-universidade, vínculos foram estabelecidos a fim de garantir atendimento e apoio aos professores. Alguns desses elos de comunicação são o Ambiente de Aprendizagem a Distância $\left(\mathrm{AMADIS}^{4}\right.$ ) e uma lista de discussão ${ }^{5}$. Em ambos, o propósito é criar uma comunidade de aprendizagem que se apóie e construa, junto e cooperativamente, sua nova forma de trabalho e seu caminho para incluir-se na na Cultura Digital. A lista de e-mail é lugar de reflexão, de troca de experiências e sugestões, de desabafos e de compartilhamento de conquistas, medos e dúvidas. $\mathrm{O}$ 
extrato a seguir foi retirado de uma mensagem enviada por uma professora da escola em 28 de agosto de 2007. O assunto da mensagem era 'Escola, que lugar é este?'

Sinceramente, faz anos que estamos nos queixando das dificuldades tanto pedagógicas (conhecimento) quanto materiais e financeiras. Só que estamos esquecendo de quem promove realmente estas mudanças somos nós. Não está sendo fácil p/ mim este novo momento na escola, mas garanto que estou aprendendo muito, estou indo devagar (no meu ritmo), cheia de medos e muitos erros. As reuniões são necessárias sim, mas o nosso empenho em realmente querer que as coisas funcionem é fundamental. Vejo nosso trabalho como uma rede, um necessita do outro p/ que dê certo. E se cada um compartilhar e estiver disponivel p/ este novo momento, tenho certeza que vamos seguir um caminho muito melhor do que estávamos até 2006.

A professora refere-se a crise que escola estava enfrentando, até o ano anterior à implementação do projeto: era preciso aumentar o número de alunos para não ser desativada. A professora apontou a necessidade da mudança de ações e não apenas de teoria, a importância do trabalho em equipe e a responsabilidade do professor em controlar o seu fazer pedagógico. Junto a essa fala da professora, está implícito o descontentamento com a apatia que assola as escolas brasileiras. Ao dizer "quem promove realmente estas mudanças somos nós", ela chama seus colegas a assumirem suas funções de liderança como legítimos instituidores da escola. Sim, os professores, os alunos, os pais, as secretarias de educação, ... todos somos instituidores que definem as regras sobre as quais a Escola está construída. Cabe, portanto, aos segmentos da sociedade assumirem suas responsabilidades e conduzirem seus esforços para modificar as antigas e construir novas estruturas e normas que possibilitem que a Escola entre em sintonia com a Cultura Digital.

Um começo plausível é reavaliar e atualizar a listagem de conteúdos mínimos que formatam a Escola, pois enquanto eles continuarem guiando as práticas pedagógicas, estas ficarão restritas a determinadas sequiências de assuntos, pouco (ou nada) coerentes com as necessidades atuais. Nesse aspecto, os PCNs são um importante suporte: priorizam conteúdos atitudinais, procedimentais e conceituais. De acordo com os parâmetros, os conteúdos conceituais são flexíveis e devem ser adaptados segundo as necessidades da comunidade escolar. Os conteúdos atitudinais e procedimentais visam, além do desenvolvimento cognitivo, o desenvolvimento psicológico, moral e ético (PCNs, 2002).

A escola LA se propôs a adaptar tempos e espaços das séries finais do EF: experimentou trabalhar com dois professores em um mesmo período e em uma mesma turma, com alterações nos horários, a fim de possibilitar períodos consecutivos para esse tipo de ação. Essa tentativa não obteve sucesso em termos práticos, visto que o horário voltou ao modelo anteriormente utilizado, mas em termos de reflexão, sim: foram os professores que identificaram a insuficiência de tempo disponível em um período (50 minutos) para trabalhar com pesquisas; também foram eles que sentiram necessidade de pedir auxílio para o colega de uma área diferente da sua.

As séries iniciais do EF foram melhor sucedidas no que diz respeito à reorganização de tempos e espaços e no trabalho com os PAs, pois não ocorreram conflitos de grupo, uma vez que cada turma contava com apenas uma professora. Não está se querendo dizer que foi uma mudança fácil. Como toda transformação, essa também causou estranhamento e exigiu adaptações por parte de professores e alunos. Esse é o segundo caso-exemplo; ele trata dos registros dos alunos sobre suas produções.

A turma da $4^{\mathrm{a}}$ série do ano de 2007 dedicou-se ao trabalho com PAs. A prática com projetos foi desenvolvida durante o ano inteiro, assim, os alunos passaram por diversas etapas nesse processo: cadastro de e-mail e depois no AVA; registros sob demanda da professora, registros espontâneos; projetos de curta duração e pesquisa V. 6 № 1, Julho, 2008 
8

mínima, projetos extensos com aprofundamento das questões de pesquisa; egocentrismo acerca da sua própria produção, cooperação com os colegas; etc. O projeto apresentado a seguir representa alguns aspectos e variáveis reconhecidas a partir desse trabalho: exposição de produção; seleção e tratamento de informações; conteúdos identificados e possíveis de serem explorados não apenas no projeto em si, mas com a turma; interações entre o autor do projeto e seus colegas e os pesquisadores; questionamentos que podem contribuir para a continuação e aprofundamento da pesquisa.

O projeto é de uma aluna da $4^{\mathrm{a}}$ série (Figuras 1 a 3 ) que está registrado no AMADIS que a escola utiliza. Todos os alunos, professores e pesquisadores da UFRGS podem interagir, acessando o projeto e o diário, registrando comentários e perguntas.

Quando realizam suas pesquisas, os alunos desenvolvem habilidades de formular questões-problema, identificar seus conhecimentos prévios, pesquisar e buscar informações, analisar e selecionar as que são pertinentes a sua pesquisa, implementar diferentes formas de apresentar e socializar suas descobertas. O professor, que orienta $\mathrm{o}$ PA, pode identificar os conteúdos escolares presentes e trabalhar com a turma a partir da curiosidade e interesse que os alunos demonstrarem. Nesse projeto, a oportunidade foi trabalhar com o sistema solar e os planetas, com a Terra e seus movimentos, com formas geométricas, com medidas, proporções, estimativas, distância e comparações.

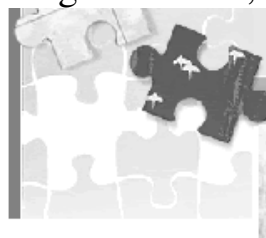
AMADIS

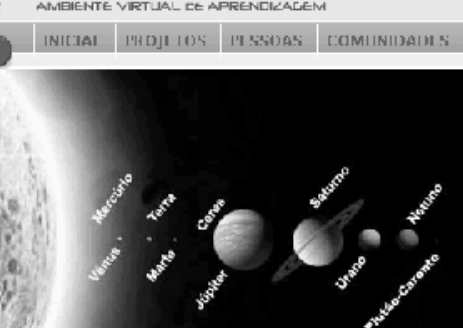

Projeto: sistema solar

sistema solar

- que sera que tem la ja descobri

sobre oque o sol e feito,sobre

quanto voce pesa nos planelas etc.

e quero descobrir muito mais

Figura 1: Projeto de aluna no AMADIS - o interesse em conhecer o sistema solar

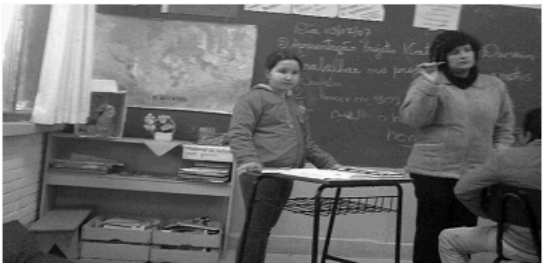

Figura 2: Apresentação do PA

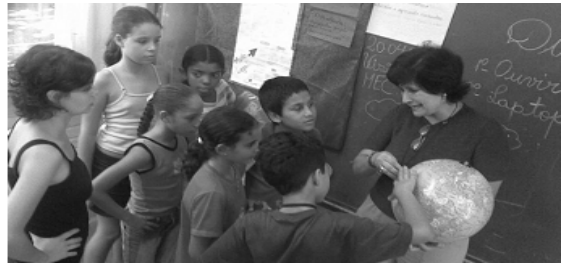

Figura 3: Discussão desencadeada pelo PA

No AMADIS, ambiente criado por uma equipe do LEC/UFRGS, foi especialmente para o desenvolvimento coletivo de PAs (Basso et al, 2006; Bittencourt et al, 2006; Monteiro et al, 2005): a aluna tem espaço para registrar suas descobertas e sua pesquisa pode ser vista, comentada, questionada e estudada por outros. Essa oportunidade de interação enriquece a pesquisa do aluno e dá subsídios para o professor saber o que pode e deve explorar com sua turma. No diário da aluna, que funciona como um blog interno ao AMADIS, há uma postagem dela "lua e terra" de 26 de abril de 2007. Nessa escrita, a aluna compartilha um pouco do que encontrou em sua pesquisa eu descobri que a lua é quatro vezes menor que a terra e o sol é 109 vezes maior que a terra em 1959 os russos construiram uma nave que foi até a lua sem ninguém dentro que fotografou o lado escuro da lua. a lua gira de 2 maneiras, em torno de si e em torno da terra.

Como o projeto da aluna fica público no ambiente, ele pode ser visitado por seus colegas e todos os outros usuários do AMADIS (que tem inscrição aberta). Todos têm a oportunidade de fazer comentários, formular perguntas, dar sugestões, enfim, interagir. Essa pesquisa teve continuidade devido às perguntas não respondidas nessa etapa. 


\section{9}

Comentário 2 - professora

Querida, sobre tua pergunta em relação a energia do sol, sugiro que fales com a tua colega que está trabalhando com raios $e$ energia. Uma ajuda a outra, ok? Beijos

Comentário 4 - colega

O ser humano pode viver sem a lua? beijos
Comentário 3 - pesquisador

Quanta coisa legal estás descobrindo! E estás me ensinando também! Tuas perguntas me fizeram pensar em mais coisas ainda: Qual é o tamanho do Sol? Será que é grande ou é pequeno? Qual a distância que ele está da Terra? Está perto ou longe? Vamos descobrir juntos?

Comentário 5 - colega

O que é nitrogeneo?

A mãe da aluna também postou um comentário no blog durante uma oficina organizada a pedido dos pais que pediram para conhecer mais como o laptop estava sendo utilizado. As famílias puderam, incluse, registrar-se no AMADIS e interagir.

oi amada da mami eu adoro essas reuniões, adoro participar dos teus aprendizados A mami apanhou um pouco mas o amigo me ajudou. Eu espero ter te deixado contente com essa mensagem, um beijo te ато тииииииииииииииииito ! A propósito tu fez um errinho de português no teu diário, escrever texto com s, é com X. tudo certo é errando que se aprende.

O terceiro caso-exemplo abordado é justamente sobre a participação da família na escola. De acordo com o depoimento de professores e dos próprios pais, essa presença nunca foi tão ativa. Se antes os pais e responsáveis freqüentavam a escola para receber o boletim de notas e conversar sobre os problemas dos alunos, a comunidade escolar passou a utilizar a escola como ponte para entrar na Cultura Digital.

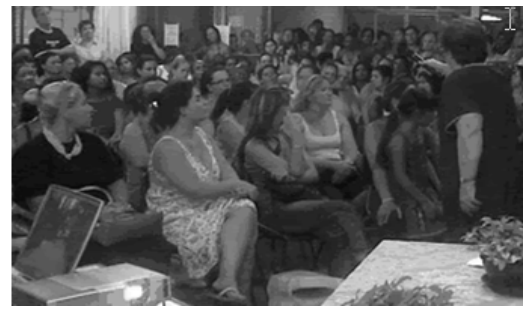

Figura 4: Primeira assembléia de pais

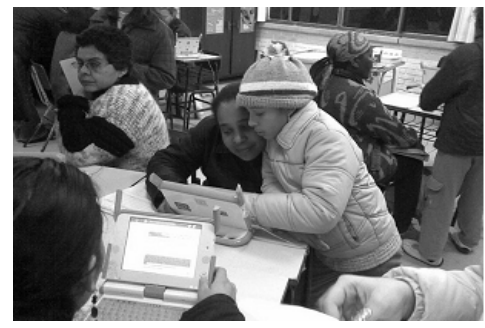

Figura 6: Oficina tecnológica com as mães

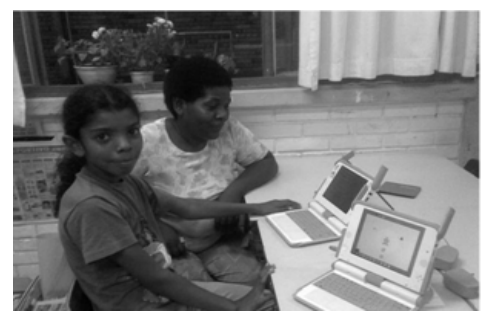

Figura 5: Avó aprendendo a utilizar o laptop

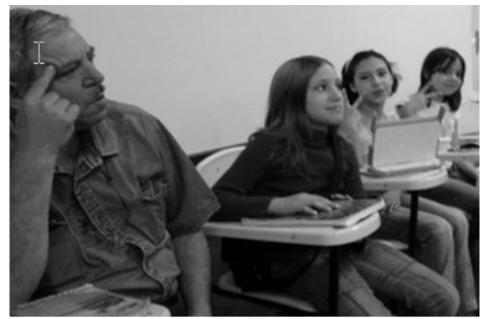

Figura 7: Pai acompanhando filhas na UFRGS

O interesse dos pais pela nova tecnologia presente na vida dos filhos, aproximou as famílias não apenas da ferramenta de estudos, mas da escola e dos próprios filhos e seus aprendizados. As imagens anteriores (Figuras 4 a 7) mostram diferentes momentos que marcaram a participação da comunidade no fazer escola: pais curiosos e preocupados com questões como segurança e aprendizagem; pais interessados e dispostos a aprender a utilizar a máquina para poderem acompanhar o que seus filhos fazem com ela e por meio dela; pais esforçados que voltam a estudar, inclusive para aprender a ler e escrever, e poder trocar mensagens; pais distantes que se reconciliam com os filhos quando percebem o que eles são capazes de fazer; ... e tantos outros casos de mudanças nas famílias. Fica o exemplo desses pais e responsáveis que, no intento de acompanhar seus filhos, colocam-se dispostos a superar a timidez com a tecnologia e 
10

aprender a utilizá-la fortalecendo os elos familiares e inserindo-se na Cultura Digital.

4. Conclusões e Possibilidades

A experiência piloto na escola Luciana de Abreu segue em atividade. Alunos, professores e comunidade continuam ampliando sua teia de aprendizagens, porém, ela ainda não ultrapassou todas as fronteiras possíveis. A comunicação via rede, por enquanto, foi estabelecida dentro da própria comunidade e com os pesquisadores (PGIE/LEC/UFRGS). Também foram estabelecidos contatos com alguns alunos de um piloto semelhante no Uruguai, com curiosos e autoridades que visitaram a escola e com pessoas que encontraram os alunos em passeios e eventos nos quais as máquinas e, principalmente, seus donos destacaram-se. Essa rede de comunicação pode ainda expandir-se e, uma vez que essa expansão de horizontes permitir vislumbrar outras realidades, a escola não mais conseguirá voltar a fechar suas janelas.

O modelo da Escola da Cultura Digital ainda não se estabeleceu, mas a discussão está aberta e as tentativas já começaram. As reflexões ecoam as mais variadas questões: como viver a Escola inserida na Cultura Digital? O que se aprende nessa Escola? Como se estuda? Essa nova Escola tem seus espaços e tempos fragmentados? As áreas do conhecimento são tratadas compartimentalizadamente? O conhecimento é sinônimo de poder? A estrutura hierárquica permanece a mesma? Quais são os objetivos dessa escola? Quem faz e quem controla as regras? Quem institui essa Escola? Como chegamos até ela?

"Caminante no hay camino, se hace camino al andar..." Antonio Machado

\section{Notas}

* Bolsista CAPES doutoranda do Programa de Pós Graduação em Informática na Educação, Universidade Federal do Rio Grande do Sul (PGIE/UFRGS). Mestre em Psicologia Social e Institucional (PPGPSI/UFRGS). Licenciada em Matemática (IMat/UFRGS). E-mail: dani @lec.ufrgs.br

** Docente do Programa de Pós Graduação em Informática na Educação, Universidade Federal do Rio Grande do Sul (PGIE/UFRGS), Coordenadora de Pesquisa do Laboratório de Estudos Cognitivos (LEC/UFRGS), Doutora em Psicologia (PUC-SP). E-mail: leafagundes@ufrgs.br

${ }^{1}$ http://nied.unicamp.br; http://www.cinted.ufrgs.br; http://www.lec.ufrgs.br

${ }^{2}$ http://www.lec.ufrgs.br/index.php/Projeto_UCA_-_Um_Computador_por_Aluno

${ }^{3}$ http://laptop.org ; http://wiki.laptop.org

${ }^{4} \mathrm{http} / / /$ uca.lec.ufrgs.br/amadis

${ }^{5}$ piloto-uca@googlegroups.com

6. Referências

AMADEU, Sérgio. Diversidade Digital e Cultura. Disponível em $<$ http://www.cultura.gov.br/ foruns_de_cultura/cultura_digital/artigos/index.php?p=27418\&more=1\&c=1\&pb=1>. 25 mai. 2007.

BASSO, M. V., MENEZES, C., FAGUNDES, L., NEVADO, R., BITTENCOURT, J. Projetos de Aprendizagem: Uma experiência mediada por ambientes telemáticos. Revista Brasileira de Informática na Educação, Rio de Janeiro, v. 14, n. 1, p. 29-39, 2006.

BATTRO, A. \& DENHAM, P. J. La educación digital: una nueva era del conocimiento. Buenos Aires: EMECE, 1997. Disponível em: <http://www.byd.com.br>. 01 out. 2004.

BITTENCOURT, J., ZORTEA, J., MENDONÇA, R., FAGUNDES, L. Criando uma plataforma para Projetos de Aprendizagem: desafios e reflexões no desenvolvimento do AMADIS.

RENOTE. Revista Novas Tecnologias na Educação, v. 4, nº 1, p. 1-10, 2006.

BRASIL. Parâmetros Curriculares Nacionais: Ensino Médio. Secretaria de Educação Média e Tecnológica. Brasília, DF, MEC/Semtec, 2002.

CASTELLS, M. A Sociedade em Rede. Volume 1. São Paulo: Paz e Terra, 1999.

COSTA, R. A Cultura Digital. São Paulo: Publifolha, 2002.

V. 6 № 1, Julho, 2008 
DWYER, T., WAINER, J., DUTRA, R. S., COVIC, A., MAGALHÃES, V., FERREIRA, L. R., PIMENTA, V. A., CLAUDIO, K. Desvendando mitos: os computadores e o desempenho no sistema escolar. Educação \& Sociedade, Campinas, v. 28, n. 101, 2007.

FAGUNDES, L. da C. \& MAÇADA, D. L. \& SATO, L. S. Aprendizes do futuro: as inovações começaram!. Brasília: Estação Palavra, 2000.

HOFFMANN, D. S. Aprender Matemática: tornar-se sujeito da sociedade em rede. 2006. DissertaçãO, Programa de Pós Graduação em Psicologia Social e Institucional, Universidade Federal do Rio Grande do Sul, Porto Alegre, 2006.

LACERDA, R., DUTRA, I., VALENTINI, N. \& CAMARGO, F. Projeto Amora 2000. Disponível em: <http://amora.cap.ufrgs.br/documentos/ProjetoAmora2000.doc>12 abr. 2001.

LACERDA, R., DUTRA, I. Tecnologias na Escola: algumas experiências e possibilidades. RENOTE. Revista Novas Tecnologias na Educação, v.1, nº.1, p. 1-8, 2003.

LÉVY, P. Cibercultura. São Paulo: Ed. 34, 1999.

MONTEIRO, V. C., MENEZES, C., NEVADO, R., FAGUNDES, L. Ferramenta de Autoria e Interação para apoio ao desenvolvimento de Projetos de Aprendizagem. RENOTE. Revista de Novas Tecnologias na Educação, v. 3, nº 2, 2005.

NEVADO, R. Espaços Interativos de Construção de Possíveis: uma nova modalidade de formação de professores. 2001. Tese, Programa de Pós Graduação em Informática na Educação, Universidade Federal do Rio Grande do Sul, Porto Alegre, 2001.

PIAGET, J. Para Onde Vai a Educação? 16ª ed. Rio de Janeiro: José Olympio, 2002. 